\title{
The clinico-pathological profile of non-Hodgkin's lymphoma in Aseer region of Saudi Arabia
}

\author{
Nawaf Alyahya ${ }^{*}$, Balkur Adiga$^{2}$, Ali Alwadei $^{3}$, Ghanem Alshahrani $^{4}$ and Fahad Alyahya ${ }^{5}$
}

\begin{abstract}
Objective: Non-Hodgkin lymphomas (NHL) are a group of neoplastic lymphoproliferative disorders, in which, its clinical spectrum, primary extra nodal variety, histopathology and Immunohistochemistry, remain lacking in Saudi Arabia. We aimed to assess the clinicopathologic patterns of $\mathrm{NHL}$ and the utility and diagnostic role of IHC immunophenotyping.

Results: Patients $>60$ years of age had the highest incidence of NHL; male: female ratio was 1.27:1. The incidence of NHL has shown a steady increase in the Aseer region from 2011 to 2014. Twenty-Five percent of our patients presented with advanced disease (Stage IV). A total of $52 \%$ of patients presented with constitutional symptoms, while $43 \%$ showed generalized lymphadenopathy. Nearly half of our patients (49\%) had primary NHL of extra nodal variety, where the stomach was the most commonly involved organ (13 cases). Diffuse large B cell lymphoma was the most common subtype of NHL in our population (59\%). Most patients (82\%) were positive for CD20 surface marker, while $60 \%$ were positive for CD45.
\end{abstract}

Keywords: Non-Hodgkin lymphoma, NHL, Clinico-pathologic, Saudi Arabia

\section{Introduction}

Non-Hodgkin lymphomas are a diverse group of neoplastic disorders, the incidence of which has shown a significant increase in rates over the year, especially in Saudi Arabia. In 2008, NHL was known as one of the most prevalent types of cancer in Saudi Arabia, with a second in rank in cancer incidence among male population (male to female ratio $=122: 100$ ) [1]. During the period from January 2009 to December 2010, the Saudi Cancer Registry recorded a total of 26,960 cases of cancer, of which a total of 1412 cases of NHL were identified, accounting for $7.2 \%$ of all cancer incidences and ranking the third [2]. More recently, the International Agency for Research on Cancer estimated an age-standardized incidence rate (ASIR) of NHL of 6.5 per 100,000 male patients with

*Correspondence: nmaalyahya@gmail.com

${ }^{1}$ Department of Internal Medicine, King Abdulaziz Medical City, Riyadh, Saudi Arabia

Full list of author information is available at the end of the article an age-standardized mortality rate (ASMR) of 4.3 per 100,000 male patients [3].

Extra nodal NHL has been reported to occur in 15 to $25 \%$ of all NHL patients in the United States (USA) and 30 to $42 \%$ in different parts of Europe [4-8]. Every single organ can be a targeted site for NHL of extra nodal variety. Data regards the incidence of primary extra nodal NHL, especially in the Saudi Arabia, remain limited.

Furthermore, diffuse large B cell lymphoma (DLBCL) has been shown to be the most frequently identified subtype of NHL [9]. Even though DLBCL is defined by the World Health Organization as a single disease entity, the variety of clinical encounter as well as genetic characteristics suggest that these neoplastic proliferations denote a dissimilar group of neoplasms [10].

Immunohistochemistry (IHC) has set the way for possible understanding of the pathogenesis of NHL as well as aiding in identifying the immunophenotype of most NHL cases [11]. Recently, IHC has become an important step in the investigation of diagnostic pathologic studies of NHL. It is used for classifying lymphatic neoplasms 
into B cell and T-cell phenotypes as well as for differential diagnosis with other malignant proliferations. CD20 is a cell surface marker expressed precisely on a majority of human B-cells [12]. Moreover, it has also been reported to be expressed on more than $90 \%$ of B-cell lymphomas; thus, it has become a good molecular goal for monoclonal antibody therapy $[13,14]$.

Due to the limited data of the clinical presentation and investigation of NHL in Saudi Arabia, a thorough insight into the clinical variety of NHL is essential for proper diagnosis and optimum treatment.

\section{Main text Methods \\ Study design and site}

This is a chart review analysis of the medical records of 100 cases diagnosed with NHL during the period from January 2011 to December 2016 at the histopathology department, Aseer Central Hospital ( $\mathrm{ACH})$. ACH is the referral tertiary care hospital catering the Aseer province with a population of 3.8 million individuals.

\section{Study population}

All patients who were diagnosed with NHL in the period from 2011 to 2016 in our setting were included. Patients who were ineligible according to the above criteria were excluded.

\section{Data gathering}

Sociodemographic data in terms of age, sex, site of biopsy was retrieved from the medical records of NHL patients. Laboratory records as regards hemoglobin $(\mathrm{Hb})$ level, White Blood Cell (WBC) count, and platelet count were also reviewed. Mild anemia was defined as $\mathrm{Hb}$ level from 9 to $12 \mathrm{~g} / \mathrm{dL}$, whereas moderate anemia was defined when $\mathrm{Hb}$ level ranged from 6 to $8 \mathrm{~g} / \mathrm{dL}$. Leucopenia was considered when WBC count was below 4000 cells $/ \mathrm{mm}^{3}$, while leukocytosis was defined when WBC count was above 11,000 cells $/ \mathrm{mm}^{3}$. Thrombocytopenia was defined as a platelet count below 150,000 cells $/ \mathrm{mm}^{3}$.

Immunohistochemistry (IHC) data was reviewed to determine the phenotype of NHL cases into B-cell and T-cell lymphomas and their subtypes. The available markers that were examined included CD3, CD20, CD30, CD8, CD5, CD15, CD45, CD43, CD21, CD23, CYCLIN D1, BCL2, BCL6, CD38, CD10, CD99, CD79, CD110, CD68, PG, M1B1, Ki 67, Vimentin, EMA, and PAX5. Patients were administered chemotherapy regimens including CHOP (Cyclophosphamide, Adriamycin, Prednisolone, and Vincristine) only, or CHOP in conjunction with other chemotherapeutic regime, or chemotherapy other than CHOP. Other chemotherapeutic regimens included BACOP (Bleomycin, Adriamycin,
Cyclophosphamide, Prednisolone, and Vincristine), CVP (Cyclophosphamide, Vincristine, and Prednisolone), ProMACE (Procatbazine, Methotrexate, Adriamycin, Cyclophosphamide, and Etoposide), and Cytoboin.

\section{Results}

The records of a total of 100 cases of NHL during the period from 2011 to 2016 were retrieved and analyzed (Fig. 1). Of which, NHL was predominant in males with a percentage of $56 \%$ as compared to females $(44 \%)$. A steady increase in the number of cases of NHL from 2011 to 2014 (from 8 cases to 22 cases) while there was a reduction in 2015 (16 cases) which increased in 2016 to reach a total of 19 cases. Upon stratifying the incidence of NHL according to age groups, NHL occurred at all age groups, however, the age group ( $>60$ years) was the most affected group (35\%) followed by the age group from 40 to 60 years (30\%). Exposure to known carcinogens, family history of lymphoma and history of any genetic diseases were unknown in most of our cases 93\%, 56\% and 56\% respectively (Table 1).

Clinical presentation with constitutional symptoms like fever, night sweats, loss of appetite, and loss of weight was observed in most patients (52\%). As regards the staging of NHL, the stage of NHL in most of our patients was unknown (59\%), whereas, stage IV was ranked the second most common stage (25\%). In terms of the site of lymphadenopathy, generalized lymphadenopathy was the most common presentation in our NHL patients (43\%). A size of $>4 \mathrm{~cm}$ was observed in $31 \%$ of patients, while $12 \%$ of patients had lymph node size of $<2 \mathrm{~cm}$. The size of lymph nodes of most of our patients was not accessible (51\%). The clinical presentation, nodal site, and size on initial presentation are summarized in (Table 2A).

Among patients with lymphadenopathy, extra-nodal organomegaly was observed in a total of 38 NHL patients. Of which, 23 patients presented with hepatomegaly; 30 patients with splenomegaly. Biopsy indicated that $49 \%$ of patients had primary lymphomas in the extra-nodal sites, with stomach being the most common site of primary extra-nodal NHL (13\%), followed by thyroid gland, and bone marrow (5\% and 5\%) respectively. Extra-nodal NHL included also other regions in the body (Table 2B).

Also, mild anemia (Hb 9-12 g/dL) was detected in $42 \%$ of patients, while moderate anemia $(\mathrm{Hb} 6-8 \mathrm{~g} / \mathrm{dL}$ ) was detected in $14 \%$ of NHL patients. On the other hand, Leucopenia (WBC count $<4000 / \mathrm{mm}^{3}$ ) was noted in a total of $27 \mathrm{NHL}$ patients, whereas, 17 patients presented with leukocytosis $\left(\mathrm{WBC}\right.$ count $>11,000 / \mathrm{mm}^{3}$ ). Moreover, thrombocytopenia (platelet count $<150,000 / \mathrm{mm}^{3}$ ) was noted in a total of 22 NHL patients. The results of bone marrow fine needle aspiration (FNA) showed a benign lymphocytic proliferation in a total of 4 patients, while 


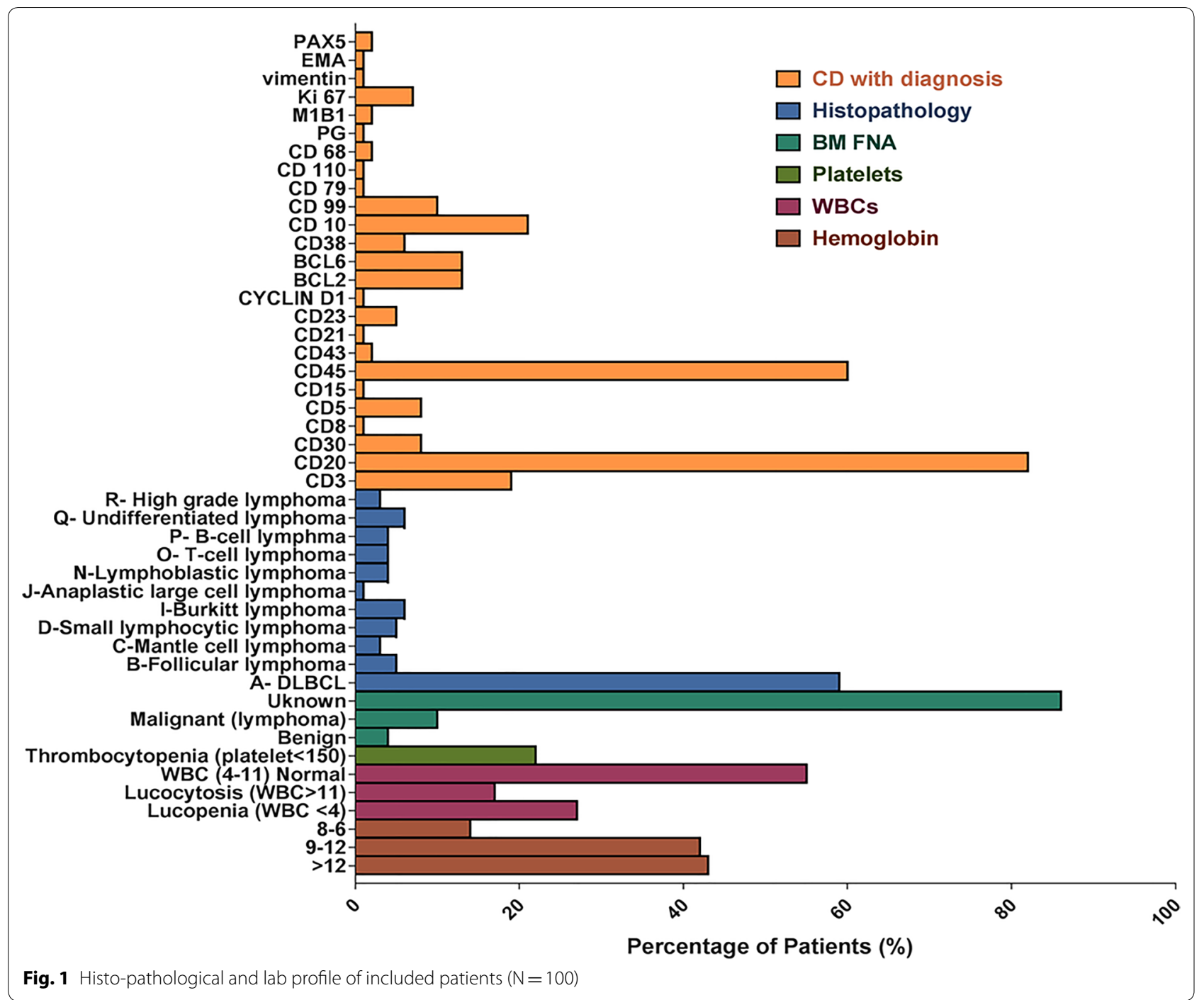

malignancy was noted in 10 cases. Noteworthy, the findings of bone marrow (FNA) was unknown in most cases (86\%).

As regards typing of NHL according to IHC markers, 82 cases were CD 20-positive; 60 cases were $C D$ 45-positive; 21 cases were CD10-positive; 19 cases were CD3-positive. Two-thirds of NHL cases were treated at our regional referral hospital while the remaining third were referred for treatment to higher centers. R-CHOP was the main chemotherapeutic regime used in $42 \mathrm{NHL}$ cases. On the other hand, 7 patients were treated with other chemotherapy in conjunction with R-CHOP, while 9 patients were given chemotherapy other than R-CHOP. Upon clinical follow up, various complications were noted in 23 patients which mainly included respiratory and gastrointestinal infections (13 cases). Other complications noted included bone marrow suppression, hypothyroidism, constipation, hypertension, femur fracture, vasculitis, and Kaposi sarcoma.

\section{Discussion}

Increased risk of NHL has been reported to be associated with various non-modifiable risk factors such as age (especially individuals of 60 years of age or more), sex, and other factor $[15,16]$.

According to age-standardized incidence rate (ASIR) we found that the age group of $>60$ years of age had the highest incidence of NHL compared to a reported $5.5 / 100,000$ in 2014 nationally with Aseer occupying the 5th most common region in Saudi Arabia [17]. Recently, a large investigation of various cancer registries within Saudi Arabia conducted by Rauf et al. [2] investigated NHL patients found that NHL has a peak incidence at the age group (40-60 years of age). We found that the 
Table 1 Socio-demographic characteristics of included patients (stratified by year) $(N=100)$

\begin{tabular}{|c|c|c|c|c|c|c|c|c|c|c|c|c|c|c|c|}
\hline & \multicolumn{14}{|c|}{ Year } & \multirow[t]{3}{*}{ P-value ${ }^{*}$} \\
\hline & \multicolumn{2}{|c|}{2011} & \multicolumn{2}{|c|}{2012} & \multicolumn{2}{|c|}{2013} & \multicolumn{2}{|c|}{2014} & \multicolumn{2}{|c|}{2015} & \multicolumn{2}{|c|}{2016} & \multicolumn{2}{|c|}{ Total } & \\
\hline & $\mathrm{N}$ & $\%$ & $\mathrm{~N}$ & $\%$ & $N$ & $\%$ & $N$ & $\%$ & $\mathrm{~N}$ & $\%$ & $\mathrm{~N}$ & $\%$ & $\mathrm{~N}$ & $\%$ & \\
\hline \multicolumn{16}{|l|}{ Age } \\
\hline $0-20$ years & 2 & 25 & 4 & 28.57 & 3 & 14.29 & 2 & 9.09 & 2 & 12.5 & 1 & 5.26 & 13 & 13 & 0.362 \\
\hline $21-40$ years & 0 & 0 & 3 & 21.43 & 5 & 23.81 & 7 & 31.82 & 3 & 18.75 & 4 & 21.05 & 22 & 22 & \\
\hline $41-60$ years & 2 & 25 & 4 & 28.57 & 7 & 33.33 & 4 & 18.18 & 8 & 50 & 5 & 26.32 & 30 & 30 & \\
\hline$>60$ years & 4 & 50 & 3 & 21.43 & 6 & 28.57 & 9 & 40.91 & 3 & 18.75 & 9 & 47.37 & 35 & 35 & \\
\hline \multicolumn{16}{|l|}{ Sex } \\
\hline Female & 3 & $37.50 \%$ & 7 & $50.00 \%$ & 11 & $52.38 \%$ & 9 & $40.91 \%$ & 6 & $37.50 \%$ & 8 & $42.11 \%$ & 44 & $44.00 \%$ & 0.932 \\
\hline Male & 5 & $62.50 \%$ & 7 & $50.00 \%$ & 10 & $47.62 \%$ & 13 & $59.09 \%$ & 10 & $62.50 \%$ & 11 & $57.89 \%$ & 56 & $56.00 \%$ & \\
\hline \multicolumn{16}{|l|}{ Nationality } \\
\hline Egyptian & 0 & 0 & 1 & $7.14 \%$ & 0 & 0 & 1 & $4.55 \%$ & 1 & $6.25 \%$ & 0 & 0 & 3 & $3.00 \%$ & $<0.001^{* *}$ \\
\hline Indonesian & 0 & 0 & 1 & 0 & 0 & 0 & 0 & 0 & 0 & 0 & 1 & 0 & 2 & 0 & \\
\hline Saudani & 0 & $0.00 \%$ & 0 & $0.00 \%$ & 0 & $0.00 \%$ & 1 & $4.55 \%$ & 0 & $0.00 \%$ & 0 & $0.00 \%$ & 1 & $1.00 \%$ & \\
\hline Saudi & 7 & 1 & 11 & 1 & 19 & 1 & 20 & 1 & 13 & 1 & 17 & 1 & 87 & 1 & \\
\hline Syrian & 0 & $0.00 \%$ & 0 & $0.00 \%$ & 0 & $0.00 \%$ & 0 & $0.00 \%$ & 1 & $6.25 \%$ & 0 & $0.00 \%$ & 1 & $1.00 \%$ & \\
\hline Yemni & 1 & 0 & 1 & 0 & 2 & 0 & 0 & 0 & 1 & 0 & 1 & 0 & 6 & 0 & \\
\hline \multicolumn{16}{|l|}{ Occupation } \\
\hline Doctor & 0 & $0.00 \%$ & 0 & $0.00 \%$ & 0 & $0.00 \%$ & 0 & $0.00 \%$ & 1 & $6.25 \%$ & 0 & $0.00 \%$ & 1 & $1.00 \%$ & $0.005^{*}$ \\
\hline Driver & 0 & $0.00 \%$ & 0 & $0.00 \%$ & 0 & $0.00 \%$ & 0 & $0.00 \%$ & 0 & $0.00 \%$ & 1 & $5.26 \%$ & 1 & $1.00 \%$ & \\
\hline Housewife & 0 & $0.00 \%$ & 3 & $21.43 \%$ & 7 & $33.33 \%$ & 2 & $9.09 \%$ & 3 & $18.75 \%$ & 4 & $21.05 \%$ & 19 & $19.00 \%$ & \\
\hline Intermediate & 0 & $0.00 \%$ & 1 & $7.14 \%$ & 0 & $0.00 \%$ & 0 & $0.00 \%$ & 0 & $0.00 \%$ & 0 & $0.00 \%$ & 1 & $1.00 \%$ & \\
\hline Maid & 0 & $0.00 \%$ & 0 & $0.00 \%$ & 0 & $0.00 \%$ & 0 & $0.00 \%$ & 0 & $0.00 \%$ & 1 & $5.26 \%$ & 1 & $1.00 \%$ & \\
\hline Manual worker & 0 & $0.00 \%$ & 0 & $0.00 \%$ & 0 & $0.00 \%$ & 0 & $0.00 \%$ & 1 & $6.25 \%$ & 0 & $0.00 \%$ & 1 & $1.00 \%$ & \\
\hline Office job & 0 & $0.00 \%$ & 0 & $0.00 \%$ & 0 & $0.00 \%$ & 0 & $0.00 \%$ & 0 & $0.00 \%$ & 1 & $5.26 \%$ & 1 & $1.00 \%$ & \\
\hline Private job & 0 & $0.00 \%$ & 0 & $0.00 \%$ & 0 & $0.00 \%$ & 1 & $4.55 \%$ & 0 & $0.00 \%$ & 0 & $0.00 \%$ & 1 & $1.00 \%$ & \\
\hline Student & 0 & $0.00 \%$ & 1 & $7.14 \%$ & 0 & $0.00 \%$ & 0 & $0.00 \%$ & 0 & $0.00 \%$ & 1 & $5.26 \%$ & 2 & $2.00 \%$ & \\
\hline Retired & 0 & $0.00 \%$ & 0 & $0.00 \%$ & 1 & $4.76 \%$ & 0 & $0.00 \%$ & 1 & $6.25 \%$ & 0 & $0.00 \%$ & 2 & $2.00 \%$ & \\
\hline Other/not working & 8 & $100.00 \%$ & 9 & $64.29 \%$ & 13 & $61.90 \%$ & 19 & $86.36 \%$ & 10 & $62.50 \%$ & 11 & $57.89 \%$ & 70 & $70.00 \%$ & \\
\hline \multicolumn{16}{|c|}{ Exposure to known carcinogens } \\
\hline $\begin{array}{l}\text { Chronic liver dis- } \\
\text { ease + bilharsesis }\end{array}$ & 0 & $0.00 \%$ & 0 & $0.00 \%$ & 1 & $4.76 \%$ & 0 & $0.00 \%$ & 0 & $0.00 \%$ & 0 & $0.00 \%$ & 1 & $1.00 \%$ & 0.566 \\
\hline Smoking & 0 & $0.00 \%$ & 0 & $0.00 \%$ & 1 & $4.76 \%$ & 2 & $9.09 \%$ & 0 & $0.00 \%$ & 0 & $0.00 \%$ & 3 & $3.00 \%$ & \\
\hline Hepatitis c +ve & 1 & $12.50 \%$ & 0 & $0.00 \%$ & 0 & $0.00 \%$ & 1 & $4.55 \%$ & 0 & $0.00 \%$ & 0 & $0.00 \%$ & 2 & $2.00 \%$ & \\
\hline liver cirrhosis & 0 & $0.00 \%$ & 0 & $0.00 \%$ & 0 & $0.00 \%$ & 1 & $4.55 \%$ & 0 & $0.00 \%$ & 0 & $0.00 \%$ & 1 & $1.00 \%$ & \\
\hline Other/Unknown & 7 & $87.50 \%$ & 14 & $100.00 \%$ & 19 & $90.48 \%$ & 18 & $81.82 \%$ & 16 & $100.00 \%$ & 19 & $100.00 \%$ & 93 & $93.00 \%$ & \\
\hline \multicolumn{16}{|c|}{ Family Hx of lymphoma } \\
\hline NO & 8 & $100.00 \%$ & 13 & $92.86 \%$ & 0 & $0.00 \%$ & 1 & $4.55 \%$ & 3 & $18.75 \%$ & 19 & $100.00 \%$ & 44 & $44.00 \%$ & $<0.001^{* *}$ \\
\hline Other/Unknown & 0 & $0.00 \%$ & 1 & $7.14 \%$ & 21 & $100.00 \%$ & 21 & $95.45 \%$ & 13 & $81.25 \%$ & 0 & $0.00 \%$ & 56 & $56.00 \%$ & \\
\hline \multicolumn{16}{|c|}{ Family Hx of other cancer } \\
\hline $\mathrm{HCC}$ & 0 & $0.00 \%$ & 0 & $0.00 \%$ & 0 & $0.00 \%$ & 1 & $4.55 \%$ & 0 & $0.00 \%$ & 0 & $0.00 \%$ & 1 & $1.00 \%$ & $<0.001^{* *}$ \\
\hline liver carcinoma & 0 & $0.00 \%$ & 0 & $0.00 \%$ & 0 & $0.00 \%$ & 1 & $4.55 \%$ & 0 & $0.00 \%$ & 0 & $0.00 \%$ & 1 & $1.00 \%$ & \\
\hline NO & 8 & $100.00 \%$ & 12 & $85.71 \%$ & 0 & $0.00 \%$ & 0 & $0.00 \%$ & 3 & $18.75 \%$ & 19 & $100.00 \%$ & 42 & $42.00 \%$ & \\
\hline Yes & 0 & $0.00 \%$ & 1 & $7.14 \%$ & 0 & $0.00 \%$ & 0 & $0.00 \%$ & 0 & $0.00 \%$ & 0 & $0.00 \%$ & 1 & $1.00 \%$ & \\
\hline Unknown & 0 & $0.00 \%$ & 1 & $7.14 \%$ & 21 & $100.00 \%$ & 20 & $90.91 \%$ & 13 & $81.25 \%$ & 0 & $0.00 \%$ & 55 & $55.00 \%$ & \\
\hline Any genetic disease (IL & & & & & & & & & & & & & & & \\
\hline deafness + aphasia & 1 & $12.50 \%$ & 0 & $0.00 \%$ & 0 & $0.00 \%$ & 0 & $0.00 \%$ & 0 & $0.00 \%$ & 0 & $0.00 \%$ & 1 & $1.00 \%$ & $<0.001^{* *}$ \\
\hline Mental retardation & 0 & $0.00 \%$ & 0 & $0.00 \%$ & 0 & $0.00 \%$ & 0 & $0.00 \%$ & 1 & $6.25 \%$ & 0 & $0.00 \%$ & 1 & $1.00 \%$ & \\
\hline NO & 7 & $87.50 \%$ & 13 & $92.86 \%$ & 0 & $0.00 \%$ & 0 & $0.00 \%$ & 3 & $18.75 \%$ & 19 & $100.00 \%$ & 42 & $42.00 \%$ & \\
\hline Unknown & 0 & $0.00 \%$ & 1 & $7.14 \%$ & 21 & $100.00 \%$ & 22 & $100.00 \%$ & 12 & $75.00 \%$ & 0 & $0.00 \%$ & 56 & $56.00 \%$ & \\
\hline
\end{tabular}


Table 1 (continued)

\begin{tabular}{|c|c|c|c|c|c|c|c|c|c|c|c|c|c|c|c|}
\hline & \multicolumn{14}{|c|}{ Year } & \multirow[t]{3}{*}{ P-value ${ }^{*}$} \\
\hline & \multicolumn{2}{|c|}{2011} & \multicolumn{2}{|c|}{2012} & \multicolumn{2}{|c|}{2013} & \multicolumn{2}{|c|}{2014} & \multicolumn{2}{|c|}{2015} & \multicolumn{2}{|c|}{2016} & \multicolumn{2}{|c|}{ Total } & \\
\hline & $\mathrm{N}$ & $\%$ & $\mathrm{~N}$ & $\%$ & $\mathbf{N}$ & $\%$ & $N$ & $\%$ & $N$ & $\%$ & $\mathbf{N}$ & $\%$ & $\mathbf{N}$ & $\%$ & \\
\hline \multicolumn{16}{|l|}{ HIV status } \\
\hline NO & 8 & $100.00 \%$ & 13 & $92.86 \%$ & 0 & $0.00 \%$ & 0 & $0.00 \%$ & 0 & $0.00 \%$ & 17 & $89.47 \%$ & 38 & $38.00 \%$ & $<0.001^{* *}$ \\
\hline Unknown & 0 & $0.00 \%$ & 1 & $7.14 \%$ & 21 & $100.00 \%$ & 22 & $100.00 \%$ & 16 & $100.00 \%$ & 2 & $10.53 \%$ & 62 & $62.00 \%$ & \\
\hline
\end{tabular}

$¥$ Chi square test; ${ }^{*} \mathrm{P}$-value $<0.05 ;{ }^{* *} \mathrm{P}$-value $<0.001$

Table 2 (A) Clinical presentation and nodal sites on initial presentation ( $N=100)$; $(B)$ organomegaly and extra-nodal sites on initial presentation $(\mathbf{N}=100)$

\begin{tabular}{|c|c|c|c|}
\hline (A) Patient profile & N (\%) & (B) Patient profile & $\mathrm{N}(\%)$ \\
\hline Constitutional symptoms & & Organomegaly (not LNs) & \\
\hline Positive (+ve) & $52(52)$ & Liver & $23(23)$ \\
\hline Negative (-ve) & $45(45)$ & Spleen & $30(30)$ \\
\hline Unknown & $3(3)$ & Pancreas & $1(1)$ \\
\hline Stage of NHL & $0(0)$ & Cecum & $1(1)$ \\
\hline | & $1(1)$ & Parotid & $2(2)$ \\
\hline I (E) & $0(0)$ & Thyroid & $2(2)$ \\
\hline I (S) & $2(2)$ & Kidney & $1(1)$ \\
\hline$\|$ & $4(4)$ & Ovary & $1(1)$ \\
\hline$\|(E)$ & $0(0)$ & Stomach & $1(1)$ \\
\hline II (S) & $3(3)$ & Colon & $0(0)$ \\
\hline III & $2(2)$ & Duodenum & $1(1)$ \\
\hline III (E) & $1(1)$ & Brain & $1(1)$ \\
\hline III (S) & $3(3)$ & & \\
\hline III (SE) & $25(25)$ & $\begin{array}{l}\text { Presentation with extranodal } \\
\text { (primary site other than } \\
\text { LNs) }\end{array}$ & \\
\hline IV & $59(59)$ & Liver & $2(2)$ \\
\hline Unknown & & Spleen & $0(0)$ \\
\hline Site of lymphadenopathy & & Pancreas & $0(0)$ \\
\hline Axillary & $3(3)$ & Cecum & $3(3)$ \\
\hline Supraclavicular & $3(3)$ & Parotid & $1(1)$ \\
\hline Cervical & $6(6)$ & Thyroid & $5(5)$ \\
\hline Mesenteric LNs & $6(6)$ & Kidney & $2(2)$ \\
\hline Paravertebral & $1(1)$ & Ovary & $1(1)$ \\
\hline Epigastric LNs & $1(1)$ & Stomach & $13(13)$ \\
\hline Nasopharyngeal & $2(2)$ & Colon & $2(2)$ \\
\hline Submandibular & $3(3)$ & Duodenum & $1(1)$ \\
\hline Generalized & $43(43)$ & Brain & $0(0)$ \\
\hline Retroperitoneal & $1(1)$ & Small bowel & $3(3)$ \\
\hline Pre-tracheal & $1(1)$ & Tongue & $2(2)$ \\
\hline \multirow[t]{3}{*}{ Unknown } & $21(21)$ & Cheek deep tissue & $2(2)$ \\
\hline & & Bone marrow (BM) & $5(5)$ \\
\hline & & Eyes & $0(0)$ \\
\hline Max. size of lymphadenopathy & & Skin & $1(1)$ \\
\hline$<2 \mathrm{~cm}$ & $12(12)$ & Breast & $2(2)$ \\
\hline $2-4 \mathrm{~cm}$ & $6(6)$ & Bones & $2(2)$ \\
\hline$>4 \mathrm{~cm}$ & $31(31)$ & Jejunum & $1(1)$ \\
\hline Unknown & $51(51)$ & Soft tissue & $1(1)$ \\
\hline
\end{tabular}

incidence of NHL was higher among men with a M:F ratio of $1.27: 1$ which shows similarity to other studies [18]. Furthermore, our study revealed a steady increase in the incidence of NHL in the Aseer region: 8 cases in 2011; 14 cases in 2012; 21 cases in 2013; 22 cases in 2014. This goes in line with a recent study conducted in Saudi Arabia which incorporated the data of all NHL patients from Saudi Cancer registry [15].

The stage of NHL was unknown in most of our patients, however, we found that quarter of our population presented with stage IV NHL which was the most common among our patients. Similarly, Rauf et al. [2] reported that the majority of their NHL patients presented with advanced disease of stage IV accounting for $44 \%$ of the total population investigated. Noteworthy, the percentage of patients whose staging data were not provided in their study was only $3 \%$ while it was $59 \%$ in our case.

Gastrointestinal (GI) tract was the most commonly involved system with the stomach being the most commonly affected organ. Afterwards, Bone Marrow (BM) and Thyroid involvement was ranked the second in place. Similarly, Diab et al. [19] examined the data of $855 \mathrm{NHL}$ cases and found that $41.4 \%$ of the total NHL cases were to be of primary extra nodal variety. The high incidence rate in our study as well as Rauf et al. [2] could reflect the impact of environmental factors related to the high prevalence of Helicobacter pylori infection among the Saudi population [20]. Our observation is also similar to the findings of other studies conducted in Saudi Arabia [2] and Kuwait [21, 22]. Such environmental exposures may prove daunting to determine which subtypes it can affect regionally. That being said, the rate of presentation with extra nodal NHL was much lower in studies conducted in the USA and others conducted in western countries [58]. Moreover, primary NHL of extra nodal variety is relatively uncommon in other parts of the world [23], while it has a surprisingly high rates in others [24]. This variation in incidence rates in different parts of the world warrants further investigation to determine the role of any attributing environmental or genetic factor.

DLBCL was the commonest type of NHL accounting for $59 \%$ of all NHL and has been found to be the most 
common subtype of NHL in western countries with an incidence rate of $30-40 \%$ of all cases $[8,25]$. It has been found to range from an incidence rate of $20 \%$ in USA to $50.5 \%$ in Thailand [26], which is even higher in Pakistan (76.4\%) [24] while in Saudi Arabia an incidence rate was reported of $6.4 \%$ in 2014 with DLBCL being the most common type similar to our finding [17].

Immunohistochemistry (IHC) remains an essential investigation for all types of lymphomas which is used for multiple purposes, which includes subtyping, prognostication, immunotherapy, differential diagnosis with other malignancies, and potentiality of targeted therapy $[11,18]$. This study revealed that $82 \%$ of NHL cases were positive for CD 20 marker while $60 \%$ were positive for CD45 marker. The unavailability of some IHC markers could account for the differences in the literature $[15,18]$.

\section{Conclusions}

NHL in the Aseer region has an increasing incidence over the years, particularly affecting those $>60$ years of age and slightly more common among men. Patients tend to present with advanced staging with constitutional symptoms and extra nodal involvement. DLBCL is the most common subtype of NHL, while CD20 marker was significant in most cases.

\section{Limitations}

Firstly, the small sample size of our study could limit the interpretation of our findings and not perceive them as absolute values. Furthermore, the lack of similar reports regionally makes it difficult to compare regions and their subtypes as well as the environmental exposures that may be a predisposing factor. Also, some data were not available for analysis which could potentially change the outcomes such as staging and size of NHL and other viral illnesses.

\begin{abstract}
Abbreviations
ACH: Aseer Central Hospital; ASIR: age-standardized incidence rate; ASMR: age-standardized mortality rate; BACOP: Bleomycin, Adriamycin, Cyclophosphamide, Prednisolone and Vincristine; BM: bone marrow; CHOP: Cyclophosphamide, Adriamycin, Prednisolone, and Vincristine; CVP: Cyclophosphamide, Vincristine and Prednisolone; DLBCL: Diffuse Large B Cell Lymphoma; FNA: fine needle aspiration; $\mathrm{Gl}$ : gastrointestinal; $\mathrm{Hb}$ : hemoglobin; $\mathrm{HC}$ : immunohistochemistry; NHL: non-Hodgkin lymphomas; ProMACE: Procatbazine, Methotrexate, Adriamycin, Cyclophosphamide and Etoposide; U.S.A: United States; WBC: white blood cell.
\end{abstract}

\section{Acknowledgements}

The authors would like to thank ACH statistical department in their help and guidance in the analysis of the data as well as ACH for providing us with the necessary tools and access to make this work complete. We like to also thank every patient who agreed to be part of our work and wish them wellness and health.

\section{Authors' contributions}

NF, BA, AA, GA and FA contributed in the designing of the study, data collection, analysis, interpretation and writing the manuscript. All authors read and approved the final manuscript.

\section{Funding}

The research was funded by Aseer Central Hospital (ACH) and supported by the Ethics-Committee Institutional Board with reference number: 2016-06-37 in providing the necessary resources for the design of the study and collection, analysis, and interpretation of data and in writing the manuscript.

\section{Availability of data and materials}

The data is archived in the hospital system with the analysis and specific material and would be provided to the proper party for non-commercial use by the authors if requested.

\section{Ethics approval and consent to participate}

The study protocol was approved according to the corresponding Ethics Committee- Institutional Review Board at Aseer Central Hospital with ethical reference number: 2016-06-37 and Committee Reference Number: HA06-B001. Furthermore, patients signed a written consent in agreement to the examination and gathering of data during the study and was archived in the hospital data system.

\section{Consent to publish}

Not applicable.

\section{Competing interests}

The authors declare that they have no competing interests.

\section{Author details}

${ }^{1}$ Department of Internal Medicine, King Abdulaziz Medical City, Riyadh, Saudi Arabia. ${ }^{2}$ Department of Pathology, King Khalid University, Abha, Saudi Arabia. ${ }^{3}$ College of Medicine, Imam Abdulrahman Bin Faisal University, Dammam,

Saudi Arabia. ${ }^{4}$ Pathology Lab, King Abdullah Hospital, Bisha, Saudi Arabia.

${ }^{5}$ College of Medicine, Bisha University, Bisha, Saudi Arabia.

Received: 11 April 2019 Accepted: 5 July 2019

Published online: 15 July 2019

\section{References}

1. Al-Eid HS, Arteh S. Cancer Incidence Report Saudi Arabia 2003. Riyadh: Kingdom of Saudi Arabia Ministry of Health National Cancer Registry; 2003.

2. Rauf MS, Akhtar S, Maghfoor I. Changing trends of adult lymphoma in the Kingdom of Saudi Arabia_comparison of data sources. Asian Pac J Cancer Prev. 2015;16(5):2069-72.

3. Globocan. The global cancer atlas. Accessed 8 May 2014.

4. Banfi A, et al. Preferential sites of involvement and spread in malignant Iymphomas. Eur J Cancer (1965). 1968:4(3):319-24.

5. d'Amore F, et al. Clinicopathological features and prognostic factors in extranodal non-Hodgkin lymphomas. Eur J Cancer Clin Oncol. 1991;27(10):1201-8.

6. Freeman C, Berg JW, Cutler SJ. Occurrence and prognosis of extranodal lymphomas. Cancer. 1972;29(1):252-60.

7. Gurney KA, Cartwright RA. Increasing incidence and descriptive epidemiology of extranodal non-Hodgkin lymphoma in parts of England and Wales. Hematol J. 2002;3(2):95-104.

8. Müller AM, et al. Epidemiology of non-Hodgkin's lymphoma (NHL): trends, geographic distribution, and etiology. Ann Hematol. 2005:84(1):1-12.

9. Chen Y, et al. Diffuse large B-cell lymphoma in Chinese patients: immunophenotypic and cytogenetic analyses of 124 cases. Am J Clin Pathol. 2010;133(2):305-13.

10. Alizadeh AA, et al. Distinct types of diffuse large B-cell lymphoma identified by gene expression profiling. Nature. 2000;403(6769):503-11. 
11. Rao IS. Role of immunohistochemistry in lymphoma. Indian J Med Paediatr Oncol. 2010;31(4):145-7.

12. Tedder TF, Engel P. CD20: a regulator of cell-cycle progression of B lymphocytes. Immunol Today. 1994;15(9):450-4.

13. Lim SH, et al. Anti-CD20 monoclonal antibodies: historical and future perspectives. Haematologica. 2010;95(1):135-43.

14. Tokunaga T, et al. De novo diffuse large B-cell lymphoma with a CD20 immunohistochemistry-positive and flow cytometry-negative phenotype: molecular mechanisms and correlation with rituximab sensitivity. Cancer Sci. 2014;105(1):35-43.

15. Alghamdi IG, et al. Incidence rate of non-Hodgkin's lymphomas among males in Saudi Arabia: an observational descriptive epidemiological analysis of data from the Saudi Cancer Registry, 2001-2008. Int J Gen Med. 2014;7:311-7.

16. Skibola CF. Obesity, diet and risk of non-Hodgkin lymphoma. Cancer Epidemiol Biomarkers Prevent. 2007;16(3):392-5.

17. Council SH. Cancer Incidence Report. Saudi Health Council. 2014. https:// nhic.gov.sa/eServices/Documents/2014.pdf.

18. Mansoor NA, Al-Kubati S. Clinicopathological correlation of non-hodgkin lymphoma an immunohistochemical profile. Eur J Pharm Med Res. 2017:4(9):768-73.

19. Al Diab AR, et al. Clinico-pathological pattern of extranodal nonHodgkin's lymphoma in Saudi Arabia. Asian Pac J Cancer Prev. 2011;12(12):3277-82.
20. Al-Moagel MA, et al. Prevalence of Helicobacter (formerly Campylobacter) pylori infection in Saudia Arabia, and comparison of those with and without upper gastrointestinal symptoms. Am J Gastroenterol. 1990;85(8):944-8.

21. AlShemmari SH, Ameen RM, Sajnani KP. Extranodal lymphoma: a comparative study. Hematology. 2008;13(3):163-9.

22. Temmim $L$, et al. Clinicopathological features of extranodal lymphomas: Kuwait experience. Oncology. 2004;67(5-6):382-9.

23. Rusinowska Z, et al. Primary forms of extralymphatic non-Hodgkin's lymphoma. Pol Tyg Lek. 1996;51(19-22):263-5.

24. Abid MB, et al. Diffuse large B cell lymphoma (DLBCL) in Pakistan: an emerging epidemic? Asian Pac J Cancer Prev. 2005;6(4):531-4.

25. Morton JE, et al. Primary gastrointestinal non-Hodgkin's lymphoma: a review of 175 British National Lymphoma Investigation cases. Br J Cancer. 1993;67(4):776-82.

26. Zahra M. Epidemiology of lymphoid malignancy in Asia. IntechOpen: Epidemiology Insights; 2012.

\section{Publisher's Note}

Springer Nature remains neutral with regard to jurisdictional claims in published maps and institutional affiliations.
Ready to submit your research? Choose BMC and benefit from:

- fast, convenient online submission

- thorough peer review by experienced researchers in your field

- rapid publication on acceptance

- support for research data, including large and complex data types

- gold Open Access which fosters wider collaboration and increased citations

- maximum visibility for your research: over 100M website views per year

At BMC, research is always in progress.

Learn more biomedcentral.com/submissions 